\title{
Depolarization Inactivation of Dopamine Neurons: An Artifact?
}

\author{
Giampaolo Mereu, ${ }^{1}$ Vanessa Lilliu, ${ }^{1}$ Pierfrancesco Vargiu,, Anna Lisa Muntoni,, ${ }^{2}$ Marco Diana, ${ }^{2, a}$ \\ and Gian Luigi Gessa ${ }^{2}$ \\ "'Bernardo Loddo," Department of Experimental Biology and "'Bernard B. Brodie," Department of Neuroscience, \\ University of Cagliari, 09124 Cagliari, Italy
}

\begin{abstract}
A widely accepted theory postulates that, in rats, chronic treatment with neuroleptics causes the depolarization inactivation of the majority of midbrain dopamine (DA) neurons. The present study was aimed to verify whether general anesthesia and/or other factors might contribute to the depolarization inactivation of A9 and A10 DA neurons. To investigate on the possible role played by DA receptor subtypes, three representatives DA antagonists were used: haloperidol (a mixed D1/D2), (-)-sulpiride (a selective D2) and SCH 23390 (a selective D1).
\end{abstract}

In agreement with previous studies, where neuronal sampling was carried out in animals under chloral hydrate anesthesia, chronic treatment with haloperidol $(0.5 \mathrm{mg} / \mathrm{kg}$ daily for 21-28 d) produced a profound reduction (about $80 \%$ ) in the number of spontaneously active A9 DA neurons. However, when neuronal sampling was performed in unanesthetized rats, the single administration of haloperidol, (-)-sulpiride, or SCH $23390(0.5,25$, and $0.3 \mathrm{mg} / \mathrm{kg}$ respectively 2$3 \mathrm{hr}$ beforehand) increased the number of spontaneously active $A 9$ and $A 10$ DA neurons and their firing rate, whereas the chronic administration of these drugs (daily for 21-28 d) failed to reduce the number of spontaneously active $A 9$ and A10 DA neurons.

The inhibitory effect of apomorphine on the firing rate of A9 and A 10 DA neurons was prevented 3-4 hr after the acute or last injection of chronic haloperidol or (-)-sulpiride. However, the inhibitory effect was potentiated $24 \mathrm{hr}$ after the last administration of the chronic regimen with these neuroleptics, but it was not influenced by either acute or chronic treatment with SCH 23390.

The results suggest that depolarization inactivation is likely to be produced as a consequence of neuroleptic-induced hyperexcitability of DA neurons combined with their stimulation by general anesthetics. Moreover, our study confirms that DA neurons become supersensitive to apomorphine after chronic neuroleptic treatment.

[Key words: dopamine, $A 9$ and $A 10$ neurons, depolarization inactivation, chronic neuroleptics, apomorphine, sulpiride, haloperidol, SCH 23390]

\footnotetext{
Received Dec. 2, 1993; revised June 22, 1994; accepted July 25, 1994.

This work was supported in part by an Italian MURST grant to G.M. We thank Dr. Alberto Musa, Mr. Stefano Aramo, and Mr. Virgilio Boi for their skillful technical assistance.

Correspondence should be addressed to G.L. Gessa, M.D., B.B. Brodie Department of Neuroscience, via Porcell 4, 09124 Cagliari, Italy.

a Present address: Institute of Biological Chemistry, University of Sassari, Via Muroni 23, Sassari, Italy.

Copyright (C) 1995 Society for Neuroscience $0270-6474 / 95 / 151144-06 \$ 05.00 / 0$
}

Two laboratories (Bunney and Grace, 1978; White and Wang, 1983) have proposed a widely accepted theory postulating that the antipsychotic effect of neuroleptics stems from the progressive silencing of dopamine (DA) neurons.

The theory is based on the electrophysiological effects of acute and chronic administration of classical neuroleptics, such as haloperidol and chlorpromazine, on DA neurons located in both substantia nigra pars compacta (SNC) and ventral tegmental area (VTA), the A9 and A10 DA neurons respectively (Dahlstrom and Fuxe, 1964). Specifically, while the acute administration of these neuroleptics was found to elevate the number of spontaneously active A9 and A10 DA neurons and their firing rate, the prolonged exposure to these drugs was found to produce a dramatic decrease in the number of spontaneously active A9 and A10 DA neurons. To explain these results, the authors postulated that while the acute neuroleptic administration would activate DA neurons by relieving them from a tonic GABAergic inhibition (Walters and Lakoski, 1977), chronic treatment would push these neurons to fire beyond their physiological limit and eventually drive them to an opposite quiescent status due to excessive membrane depolarization. This condition, reminiscent to that early described by Hodgkin and Huxely (1952), has been defined as a neuroleptic-induced depolarization inactivation or depolarization block of DA neurons (Bunney and Grace, 1978; Chiodo and Bunney, 1983; White and Wang, 1983).

Further studies revealed that chronic treatment with atypical neuroleptics, such as sulpiride, thioridazine, and clozapine, led to a selective reduction in the number of spontaneously active A10 DA neurons, leaving unchanged or even increased that of active A9 DA neurons (Chiodo and Bunney, 1983; White and Wang, 1983; Skarsfeldt, 1988a).

Popularity of the depolarization inactivation theory stems from the fact that the time-dependent induction of depolarization inactivation in A10 DA neuronal firing, a common feature of chronic treatment with both classical and atypical neuroleptics, offers a reasonable explanation for the temporal discrepancy between the immediate blockade of DA receptors produced by these drugs and the delayed onset of their therapeutical effect. Moreover, the ability of atypical neuroleptics to selectively decrease active A10 DA neurons has been correlated with their preferential interaction with the meso-limbic/meso-cortical DAergic system and has been proposed as a valid explanation for their lower potentiality in producing extrapyramidal side effects.

However, we observed several inconsistencies within the electrophysiological data and between these data and certain biochemical results. Thus, the number of active DA neurons in control animals as well as the percent reduction following chron- 
ic neuroleptics show a wide variability in reports from different laboratories and even in successive reports from the same laboratory (Bunney and Grace, 1978; Chiodo and Bunney, 1983; White and Wang, 1983; Skarsfeldt, 1988a). While the chronic administration of (-)-sulpiride was found to selectively silence A10 DA neurons by White and Wang (1983), it behaved like haloperidol in suppressing both A9 and A10 DA neurons in Chiodo and Bunney's report (1983). The repeated administration of the DA-D1 receptor antagonist SCH 23390 has been found to reduce the number of active A9 and A10 DA neurons (Skarsfeldt, 1988b), that of A10 DA neurons only (Goldstein and Litwin, 1988), and to be completely ineffective (Esposito and Bunney, 1989). Furthermore, since the allosteric activation of tyrosine hydroxylase is considered the biochemical correlate of neuroleptic-induced stimulation of DA neurons (Zivkovic et al., 1974), it should parallel DAergic firing. Tolerance to haloperidol-induced activation of the enzyme is produced after chronic treatment, as would be expected if DA neurons were in a condition of depolarization inactivation. However, against such a possibility is the fact that tolerance can be surmounted by increasing haloperidol dosage (Tissari et al., 1979), a response expected only if DA neurons were to be further stimulated by the drug.

Finally, a recent brain microdialysis study by Moghaddam and Bunney (1993) has shown that chronic treatment with haloperidol reduces neither basal DA release in the striatum nor its increase after a challenge with haloperidol. These findings are difficult to reconcile with the silencing of DA neurons by their depolarization inactivation.

We hypothesized that these discrepancies might reside in some technical detail, such as the sampling protocol and the type and level of anesthesia. In an attempt to clarify this matter, the effect of acute and chronic administration of three representatives DA receptor antagonists: (-)-sulpiride, SCH 23390 and haloperidol (a D2, D1, and a mixed D1/D2 receptor antagonist, respectivcly), on the number of spontancously active A9 and A10 DA neurons and their firing rate was reexamined in unanesthetized rats. Moreover, the effect of chronic haloperidol on A9 DA neurons, in chloral hydrate anesthetized rats, was also compared.

\section{Materials and Methods}

We followed an experimental protocol similar to that of Chiodo and Bunney (1983). Slight modifications were, however, introduced as stated. Experiments were designed in accordance with the National Institutes of Health (Publication 80-23) and Society for Neuroscience instructions (approved April, 1984). Moreover, the experimental protocol of this study has been approved by the Ethic Committee Investigation Review Board of the University of Cagliari.

\section{Animals}

Male Sprague-Dawley CD rats (Charles River, Como, Italy) with an initial weight of $125-150 \mathrm{gm}$ were used. Rats were housed four per cage at $22^{\circ} \mathrm{C}$ with light on from 0800 to $2000 \mathrm{hr}$. They had free access to food and tap water. Food consisted of dried chops of a balanced diet (DIET 4-RF 25, Charles River, Como, Italy). At the end of chronic treatment, control, (-)-sulpiride- and SCH 23390-treated rats weighed about $300-350 \mathrm{gm}$. Animals receiving chronic haloperidol weighed about $50 \mathrm{gm}$ less than control rats.

\section{Treatment}

Rats were divided into different groups as follows.

Control rats. These included: (a) untreated animals $(N=4)$, (b) rats receiving a single injection of saline $(1.0 \mathrm{ml} / \mathrm{kg}) 2$ to $3 \mathrm{hr}$ before the recording $(N=8)$, and (c) rats receiving a daily administration of $0.9 \%$ saline $(1.0 \mathrm{ml} / \mathrm{kg})$ for $21-28$ consecutive $\mathrm{d}(N=12)$. Data from these different groups of animals were pooled since no differences among them were observed.

Acute treatment. Different groups of rats ( $N=16$ per group) received a single administration of haloperidol, (-)-sulpiride, or SCH 23390 at the doses of $0.5,25$, and $0.3 \mathrm{mg} / \mathrm{kg}$, respectively.

Chronic treatment. Different groups of animals $(N=16$ per group) were treated with haloperidol, $(-)$-sulpiride, or SCH 23390 at the doses of $0.5,25$, and $0.3 \mathrm{mg} / \mathrm{kg}$, respectively, daily for $21-28 \mathrm{~d}$. Data from different treatment periods were pooled, since no differences among them were present. To perform the experiments in chloral hydrate anesthesia (see below), two additional group of eight rats were chronically treated with $0.9 \%$ saline and haloperidol, respectivcly.

Neuroleptics or their vehicle solutions were injected subcutaneously (s.c.) in a volume of $1.0 \mathrm{ml} / \mathrm{kg}$. Sampling of spontaneously active DA neurons, by single unit recording, began approximately $2 \mathrm{hr}$ after the acute administration, or after the last injection of chronic neuroleptic treatment.

To test for DA autoreceptor sensitivity to apomorphine, the latter was injected i.v. at exponentially increasing doses every 2 min (final cumulative doses were: $1,2,4,8,16,32,64,128,256$, and $512 \mu \mathrm{g} / \mathrm{kg}$ ) while recording the last neuron sampled in each animal. Data were used to calculate, by probit analysis, the effective dose inhibiting by $50 \%$ $\left(E D_{50}\right)$ the spontaneous firing rate. Separate experiments were performed to test the effect of apomorphine on A9 DA neurons $24 \mathrm{hr}$ after the last administration of chronic neuroleptics.

\section{Anesthetized rats}

Anesthesia was induced with the intraperitoneal (i.p.) injection of 400 $\mathrm{mg} / \mathrm{kg}$ of chloral hydrate and then maintained, starting approximately $60 \mathrm{~min}$ later, with the i.p. infusion (via a butterfly needle) of chloral hydrate at the rate of $120 \mathrm{mg} / \mathrm{kg} / \mathrm{hr}$. Dosage of anesthetic corresponded to that used in previous studies (Bunney and Grace, 1978; White and Wang, 1983). Moreover, the slow infusion of chloral hydrate allowed us to maintain a constant level of anesthesia throughout the recording session, as indicated by the complete absence of nociceptive responses.

Rats were mounted in a stereotaxic apparatus (David Kopf, Tujunga, CA) with the skull flat (tooth bar set at $-2.3 \mathrm{~mm}$ ). The scalp was reflected and a hole ( $\phi$ about $2.5 \mathrm{~mm}$ ) overlying SNC or VTA was drilled in the skull. Under stereomicroscope vision the dura mother was carefully cut and residual bone flakes removed to avoid to break the microelectrode tip during its brain penetration. Expired $\mathrm{CO}_{2}$ concentration $(3.5-4.0 \%)$, heart rate $(250-300$ beats $/ \mathrm{min})$, rectal temperature $\left(36.5-37.0^{\circ} \mathrm{C}\right)$ were continuously monitored.

\section{Unanesthetized rats}

Rats were prepared as previously described in detail (Mereu et al., 1985). Briefly, tracheal intubation and vein cannulation, stereotaxic immobilization, and all surgery were carried out under general anesthesia by halothane inhalation $(2.5-3.0 \% \mathrm{v} / \mathrm{v}$ in room air). Subsequently, all surgical wounds and stereotaxic pressure points were infiltrated with a longacting local anesthetic ( $2 \%$ mepivacaine- $\mathrm{HCl})$ and the animal was paralyzed by an i.v. dose $(5 \mathrm{mg} / \mathrm{kg})$ of $d$-tubocurarine. Upon spontaneous breathing cessation, the trachea was connected to an artificial respirator through which room air was delivered at the rate of 80-100 strokes/ min with a tidal volume set at $0.8-1.0 \mathrm{~cm}^{3}$.

\section{Single cell recording}

Autofilling borosilicate glass capillaries (GC $150 \mathrm{~F}$, Clark, England), with a single inner filament, were pulled with a vertical puller (PE-2, Narishige, Tokyo). To obtain a low resistance $(3.5-4.5 \mathrm{M} \Omega$ at $256 \mathrm{~Hz}$ in $0.9 \% \mathrm{NaCl})$ with a small tip $(0.5-1.0 \mu \mathrm{m}$ outside diameter) and a relative low concentration of the electroconductive solution, micropipettes were filled with freshly filtered of Na-acetate $(0.5 \mathrm{M})$ and Pontamine sky blue $(1 \% \mathrm{w} / \mathrm{v})$. Moreover, the single inner Fiberglas filament ensured a high reproducibility of their physical characteristics. Extracellular action potentials were monitored and processed using a conventional line of electronic amplification (Mereu et al., 1985).

\section{Identification of DA neurons}

DA neurons were recognized on the basis of their well-known electrophysiological and neuropharmacological characteristics (Bunney et al., 1973; Mereu et al., 1985; Chiodo, 1988). Briefly, DA neurons, located 
Table 1. Effect of chronic haloperidol on the number of spontaneously active A9 DA neurons and their firing rate in chloral hydrate anesthetized rats

\begin{tabular}{lll} 
Treatment & $\begin{array}{l}\text { Neurons/ } \\
\text { track }\end{array}$ & $\begin{array}{l}\text { Firing rate } \\
\text { (spikes/sec) }\end{array}$ \\
\hline Control & $0.94 \pm 0.12$ & $4.04 \pm 0.21$ \\
Chronic haloperidol & $0.17 \pm 0.02^{*}$ & $6.09 \pm 0.36^{*}$
\end{tabular}

Haloperidol was administered at $0.5 \mathrm{mg} / \mathrm{kg}$ (s.c.) once daily for 21-28 d. Last administration was given 2-3 hr before testing. Control rats received the corresponding vehicle. Each value indicates the mean ( \pm SEM) of encountered neurons' track and their firing rate. Sample size was eight rats per group. ${ }^{*} p<0.01$, with respect to control value $(t$ test).

within the A9 and A10, show a wide $(2.5-5.0 \mathrm{msec})$, biphasic $(+/-)$ or triphasic $(+/-/+)$ extracellular action potential in the filtered $(-3 \mathrm{~dB})$ bandpass $(100-2500 \mathrm{~Hz}$ ), and have a typically slow regular or bursting firing rate of one to eight spikes/sec.

\section{Sampling DA neurons}

The number of spontaneously active DA neurons/track was estimated by systematically passing the microelectrode in a stereotaxically defined parallelepiped of brain tissue that contained either the A9 DA neurons ( 2.9 to $3.4 \mathrm{~mm}$ anterior; 1.9 to $2.5 \mathrm{~mm}$ lateral with respect to the lambda point, and 6.8 to $7.8 \mathrm{~mm}$ ventral to the cortical surface) or A10 DA neurons ( 2.8 to $3.3,0.4$ to 0.9 , and 7.8 to 8.0 , respectively) according to the coordinates of Paxinos and Watson's atlas (1982).

The brain areas explored corresponded to that analyzed in previous studies (Bunney and Grace, 1978; Chiodo and Bunney, 1983; White and Wang, 1983). Microelectrodes were lowered into the brain under stereomicroscope control using a fine micromanipulator (SN 20, Narishige, Tokyo). The number of spontaneously active DA neurons encountered from the dorsal to the ventral edges of the block was counted. Once penetration was completed, the microelectrode was withdrawn from the brain, moved $100 \mu \mathrm{m}$ rostrocaudally or mediolaterally within the defined area, and then lowered again. The penetration sequence followed a random order. Of each group of animals half were used for sampling of A9 DA neurons and the other half for A10 neurons. The number of encountered neurons, having the electrophysiological characteristics of DA neurons, was averaged over the number of electrode penetrations (usually 10 ). The experimenter was unaware of the treatment.

\section{Histology}

At the end of each experiment, the last recording site was marked by the iontophoretic ejection of Pontamine sky blue ( 2 to $5 \mu \mathrm{A}$ of cathodal current for $10 \mathrm{~min}$ ) through the recording electrode. The animal was then sacrificed with an i.v. injection of $\mathrm{Na}$ pentobarbital $(50 \mathrm{mg} / \mathrm{kg})$. Consequently, the upper part of the body was perfused (the descending aorta clamped) with $0.9 \%$ saline followed by $10 \%$ buffered formaldehyde, the brain removed, and kept for $24 \mathrm{hr}$ in $10 \%$ formaldehyde. The position of the blue dye (a spot of $20-50 \mu \mathrm{m}$ diameter) was verified by a light microscope in serial slices $(50 \mu \mathrm{m})$, stained with cresyl violet, and counterstained with neutral red. The histology confirmed that all neurons included in the present study were located within the A9 and $\mathrm{A} 10$ areas.

\section{Drugs}

The following drugs were used: haloperidol (Serenase, Janssen, Beerse, Belgium) and (-)-sulpiride (Ravizza, Muggiò, Italy) as the commercially available solutions; $\mathrm{SCH} 23390$ (Schering Corporation, Bloomfield, NJ); apomorphine HCl (Sigma, St. Louis, MO). Haloperidol and (-)-sulpiride solutions were diluted in $0.9 \% \mathrm{NaCl}$; SCH 23390 was suspended in a Tween 80 solution $\left(4 \%\right.$ in $\left.\mathrm{H}_{2} \mathrm{O}\right)$; apomorphine $\mathrm{HCl}$ was freshly dissolved in $\mathrm{H}_{2} \mathrm{O}$ containing $0.2 \%$ ascorbic acid. Injection volumes were $1 \mathrm{ml} / \mathrm{kg}$ of body weight. Dosages refer to the salt form of all used compounds.

\section{Statistics}

Values are given as arithmetic means \pm SEM. Statistical significance between groups was determined by analysis of variance (ANOVA) fol-
Table 2. Effect of acute and chronic treatment with neuroleptics on the inhibitory effect of apomorphine on the firing rate of A9 DA neurons in unanesthetized rats

\begin{tabular}{lcl} 
& \multicolumn{2}{c}{$\begin{array}{l}\mathrm{ED}_{50} \text { of apomorphine }(\mu \mathrm{g} / \mathrm{kg}, \text { i.v. }) / \text { time after } \\
\text { last treatment }\end{array}$} \\
\cline { 2 - 3 } Treatment & $3-4 \mathrm{hr}$ & $24 \mathrm{hr}$ \\
\hline Control & $21.4 \pm 6.3$ & N.T. \\
A. haloperidol & $265.3 \pm 34.6^{* * *}$ & N.T. \\
A. (-)-sulpiride & $204.5 \pm 28.8^{* * *}$ & N.T. \\
A. SCH 23390 & $35.6 \pm 8.4$ & N.T. \\
C. haloperidol & $127.4 \pm 21.3^{* * \dagger}$ & $8.1 \pm 0.3^{*}$ \\
C. $(-)$-sulpiride & $95.6 \pm 15.7^{* * \dagger}$ & $5.3 \pm 0.5^{* *}$ \\
C. SCH 23390 & $32.6 \pm 6.9$ & $20.4 \pm 5.4$
\end{tabular}

The effective dosc $\left(\mathrm{ED}_{50}\right)$ inhibiting the spontancous firing rate of $\mathrm{A} 9 \mathrm{DA}$ ncurons by $50 \%$ was calculated by probit analysis, administering apomorphine intravenously every $2 \mathrm{~min}$ at exponentially increasing (ratio 2) doses starting from $1 \mu \mathrm{g}$ / $\mathrm{kg}$. Drug regimen was as indicated in the legend of Figure 1. Sample size was seven rats for control and eight rats for the other groups. Only one cell per animal was tested. A., acute administration; C., chronic administration; N.T., not tested. ${ }^{* * *} p<0.005,{ }^{* *} p<0.01,{ }^{*} p<0.05$, with respect to control value. $\dagger p<0.01$, with respect to acute administration $(t$ test).

lowed by two-tailed Dunnett's test. Each neuron was monitored for 5 min and its firing rate was calculated by counting the number of spikes generated over single periods of $10 \mathrm{sec}$ and averaging $18-24$ of these periods.

\section{Results}

\section{Anesthetized rats}

\section{Chronic haloperidol}

As shown in Table 1, the mean number of spontaneously active A9 DA neurons encountered in each microelectrode penetration in control anesthetized rats was $0.94 \pm 0.12$. They exhibited an average discharge rate of $4.04 \pm 0.21$ spikes/sec. In animals chronically treated with haloperidol $(0.5 \mathrm{mg} / \mathrm{kg}$ s.c. daily for $21-$ 28 d) 2-3 hr after the last injection, the number of spontaneously active neurons was found reduced to about the $20 \%[t(14)=$ $6.33, p<0.001]$, while the firing rate of the remaining active neurons was $6.09 \pm 0.36$ spikes/sec, a $50 \%$ higher than in control rats $[t(14)=4.25, p<0.001]$.

\section{Unanesthetized rats}

As shown in Figure 1 (left panels), the mean number $A 9$ and A10 DA neurons/track in unanesthetized control rats was 1.08 \pm 0.16 and $1.58 \pm 0.14$, respectively. They exhibited an average firing rate (right panels) of $3.24 \pm 0.21$ and $4.39 \pm 0.34$ spikes/ sec, respectively.

\section{Acute neuroleptics}

The acute administration of haloperidol, (-)-sulpiride, and $\mathrm{SCH}$ 23390 at the doses of $0.5,25$, and $0.3 \mathrm{mg} / \mathrm{kg}$, respectively, 2-3 $\mathrm{hr}$ beforehand, significantly increased the number of spontaneously active $\mathrm{A} 9$ and $\mathrm{A} 10 \mathrm{DA}$ neurons $[F(6,48)=37.5, p<$ $0.01]$ and their firing rate $[F(6,48)=28.4, p<0.01]$.

\section{Chronic neuroleptics}

Figure 1 also shows that when the sampling was performed 2$3 \mathrm{hr}$ after the last injection of the chronic administration of haloperidol, (-)-sulpiride, or SCH $23390(0.5,25$, and $0.3 \mathrm{mg}$ / $\mathrm{kg}$, s.c., respectively, daily for 21-28 d), the number of spontaneously active A9 and A10 DA neurons was found not decreased with respect to control value $[F(6,48)=2.28 \mathrm{NS}]$. 


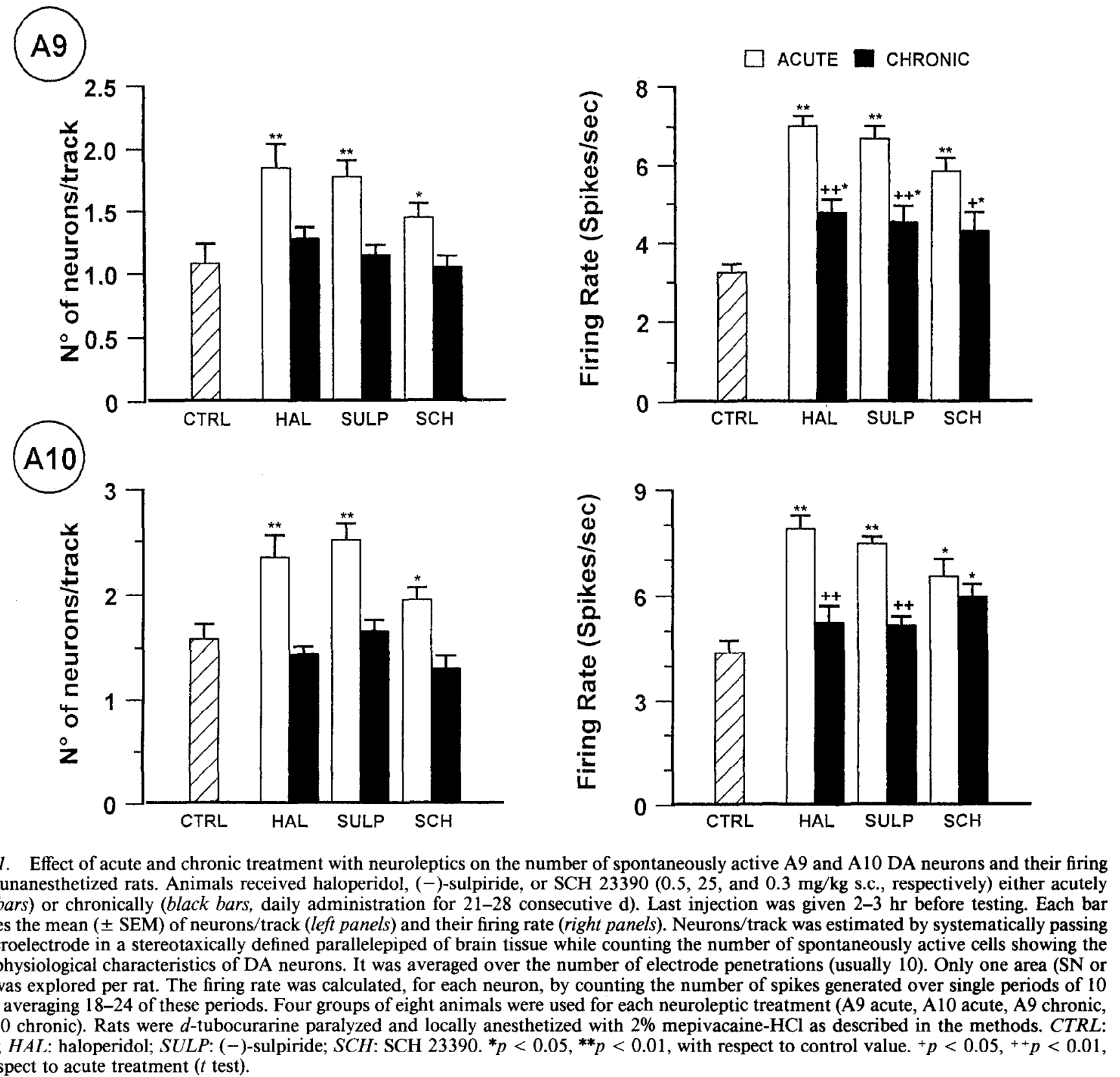

Figure 1. Effect of acute and chronic treatment with neuroleptics on the number of spontaneously active A9 and A10 DA neurons and their firing rate in unanesthetized rats. Animals received haloperidol, (-)-sulpiride, or SCH $23390(0.5,25$, and $0.3 \mathrm{mg} / \mathrm{kg}$ s.c., respectively) either acutely (white bars) or chronically (black bars, daily administration for 21-28 consecutive d). Last injection was given 2-3 hr before testing. Each bar indicates the mean $( \pm$ SEM) of neurons/track (left panels) and their firing rate (right panels). Neurons/track was estimated by systematically passing the microelectrode in a stereotaxically defined parallelepiped of brain tissue while counting the number of spontaneously active cells showing the electrophysiological characteristics of DA neurons. It was averaged over the number of electrode penetrations (usually 10 ). Only one area (SN or VTA) was explored per rat. The firing rate was calculated, for each neuron, by counting the number of spikes generated over single periods of 10 sec and averaging 18-24 of these periods. Four groups of eight animals were used for each neuroleptic treatment (A9 acute, A10 acute, A9 chronic, and AlO chronic). Rats were $d$-tubocurarine paralyzed and locally anesthetized with $2 \%$ mepivacaine-HCl as described in the methods. $C T R L$ : control; HAI: haloperidol; SULP: (-)-sulpiride; $S C H$ : SCH $23390 .{ }^{*} p<0.05,{ }^{* *} p<0.01$, with respect to control value. ${ }^{+} p<0.05,{ }^{++} p<0.01$, with respect to acute treatment $(t$ test).

Actually, in rats chronically treated with haloperidol and (-)sulpiride, the number of active A9 DA neurons was slightly, although not significantly, higher than in control rats $[t(13)=$ 1.12 and 0.71 , respectively). However, in rats chronically treated with any one of the three neuroleptics, the firing rate of A9 and $\Lambda 10 \mathrm{DA}$ neurons was found higher than in control rats, as indicated in Figure 1.

If we compare, for each neuroleptic, the number of active A9 and A10 DA neurons found in acute versus chronically treated group, it is evident that this number is significantly lower $[F(5$, $42)=8.31, p<0.05]$ after the chronic administration. Similarly, the firing rate of DA neurons in animals chronically treated with haloperidol, (-)-sulpiride, or SCH 23390, although higher than that in control rats, was found reduced $[F(5,42)=9.88, p<$ 0.05 ] with respect to that observed in rat acutely treated with the same neuroleptic.

\section{Apomorphine response}

To verify whether the acute or chronic neuroleptic treatment had modified DA autoreceptor sensitivity, the last DA cell sampled in each rat was tested for the inhibitory effect of i.v. apomorphine.

As shown in Table 2, neither acute nor chronic administration of SCH 23390 changed the $\mathrm{ED}_{50}$ of apomorphine. On the other hand, 2-3 hr from the acute treatment or the last dose of chronic treatment with haloperidol or (-)-sulpiride, A9 DA neurons were less sensitive to the inhibitory effect of apomorphine. Similar results were obtained with A10 DA neurons (results not shown).

In separate groups of animals ( $N=8$ each group) chronically treated with neuroleptics the inhibitory effect of apomorphine was tested $24 \mathrm{hr}$ after the last dose. At this time the number of 
spontaneously active A9 DA neurons and their firing rate were not statistically different from control values (results not shown). However, as reported in Table 2 the inhibitory effect of apomorphine was potentiated following chronic haloperidol and (-)-sulpiride but was not modified after chronic SCH 23390.

\section{Discussion}

Our results obtained in chloral hydrate anesthetized rats have confirmed previous studies (Bunney and Grace, 1978; White Wang, 1983; Skarsfeldt, 1988a) showing that chronic treatment with haloperidol causes a profound reduction in the number of spontaneously active A9 DA neurons. However, when neuronal sampling was carried out in unanesthetized animals, we not only found, as expected, that the acute administration of different neuroleptics increased the number and firing rate of spontaneously active DA neurons, but also that chronic treatment with these drugs failed to reduce the number of spontaneously active A9 and A10 DA neurons. Actually, in unanesthetized rats, 2$3 \mathrm{hr}$ following the last administration of chronic haloperidol and (-)-sulpiride, the number of active DA neurons encountered in the A9 was slightly, although not significantly, higher than in control rats, while the chronic treatment with $\mathrm{SCH}$ 23390 did not modify the number of active A9 and A10 DA neurons.

Moreover, rats chronically treated with haloperidol, (-)-sulpiride and SCH 23390 showed a firing rate of A9 and A10 DA neurons higher than in control rats, although lower than that observed in rat acutely treated with the same drug. This finding indicates that, at the time of recording session (2-3 hr after the last injection), when the blockade of DA receptors was still operative, a tolerance to the stimulant effect of neuroleptics had developed.

Additionally, we have shown that in unanesthetized rats, 24 hr after termination of the chronic treatment with the DA-D2 receptor antagonists haloperidol or (-)-sulpiride, it was evident an increased sensitivity to the inhibitory effect of apomorphine on DA neuronal firing. This observation confirms that DA autoreceptors become supersensitive after chronic neuroleptic treatment (Biggio et al., 1980).

The failure to observe the depolarization inactivation phenomenon in unanesthetized animals supports our hypothesis that this condition is the consequence of the summation of at least two factors that simultaneously stimulate or increase the excitability of DA neurons: the neuroleptics and the general anesthesia by chloral hydrate. Indeed, chronic DA receptor blockade by neuroleptics has been shown to drive the resting membrane potential of DA neurons toward more positive values (Chiodo, 1988; Grace and Bunney, 1986). On the other hand, general anesthetics, such as diethyl ether nitrous oxide and halothane chloral hydrate and barbiturates have been shown to stimulate DA neurons (Bunney et al., 1973; Mereu et al., 1984), apparently by removing a GABAergic inhibitory control (Walters and Lakoski, 1977; Gessa et al., 1986; Mereu and Biggio, 1990).

However, general anesthesia does not seem to be the only factor in determining the depolarization inactivation of DA neurons, since Bunney and Grace (1978) have observed the same phenomenon both in chloral hydrate and in unanesthetized, gallamine-paralyzed rats. Although we do not have an obvious explanation for the discrepancy between their report and the present study, we might hypothesize that other cxcitatory causes, perhaps inherent to the sampling procedure, may also contribute to the development of depolarization inactivation of DA neurons. For instance, in our protocol, great care was taken to reduce tissue damage and electrolyte leakage.

One might argue that in our experiments the animal stress, secondary to stereotaxic immobilization in the unanesthetized preparation, might have counteracted the neuroleptic-induced depolarization inactivation of DA neurons. Against such possibility is the evidence that acute stress by immobilization actually activates DA transmission (Fadda et al., 1985; Imperato et al., 1991). Therefore, this condition should constitute an additional factor toward the development of depolarization inactivation of DA neurons.

In conclusion, we suggest that depolarization inactivation is an artefact brought about by the combination of the increased excitability of DA neurons produced by chronic neuroleptics and the neuronal stimulation produced by general anesthetics. However, we cannot rule out other factors, related to the sampling methodology, that might have increased the excitability of these neurons. Therefore, our data argue against the accepted view that depolarization inactivation of DA neurons may provide a reasonable explanation for the delayed therapeutic effect of neuroleptics.

On the other hand, our results support the view that the chronic administration with neuroleptics produces an upregulation of DA autoreceptors (Biggio et al., 1980). Indeed, $24 \mathrm{hr}$ after the interruption of chronic treatment with the DA-D2 receptor antagonists haloperidol and (-)-sulpiride, the inhibitory effect of apomorphine on the spontaneous firing rate of A9 DA neurons was found potentiated, suggesting the development of an enhanced sensitivity of DA autoreceptor to endogenous DA. This might explain the fact that the stimulant effect of neuroleptics on DA neurons (measured as an increase in the number of active neurons and their firing rate) was reduced after the chronic administration. Therefore, the development of tolerance to the firing activating effect should result in a facilitation of neuroleptic-induced blockade of DAergic transmission, and it might contribute to the emergence of the antipsychotic effect of these drugs.

\section{References}

Biggio G, Casu M, Klimek V, Gessa GL (1980) Dopamine synthesis: tolerance to haloperidol and supersensitivity to apomorphine depend on presynaptic receptors. In: Advances in biochemical psychopharmacology, Vol 2, Long term effect of neuroleptics (Cattabeni F, Raccagni A, Spano PF, Costa E, eds), pp 17-22. New York: Raven.

Bunney BS, Grace AA (1978) Acute and chronic haloperidol treatment: comparison of effect on nigral dopaminergic activity. Life Sci 23:1715-1728.

Bunney BS, Walters J, Roth RH, Aghajanian GK (1973) Dopaminergic neurons: effect of antipsychotic drugs and amphetamine on single cell activity. J Pharmacol Exp Ther 185:560-571.

Chiodo LA (1988) Dopamine-containing neurons in the mammalian central nervous system: electrophysiology and pharmacology. Neurosci Biobehav Rev 12:49-91.

Chiodo LA, Bunney BS (1983) Typical and atypical neuroleptics: Differential activity of chronic administration on the activity of $A 9$ and A10 midbrain dopaminergic neurons. J Neurosci 3:1607-1619.

Dahlstrom A, Fuxe K (1964) Evidence for the existence of monoamine-containing neurons in the central nervous system. I Demonstrating of monoamines in the cell bodies of brain stem neurons. Acta Physiol Scand [Suppl] 62(232):1-55.

Esposito E, Bunney BS (1989) The effect of acute and chronic treatment with SCH 23390 on the spontaneous activity of midbrain dopamine neurons. Eur J Pharmacol 162:109-113.

Fadda F, Mosca E, Meloni R, Gessa GL (1985) Ethanol-stress interaction on dopamine metabolism in the medial prefrontal cortex. Alcohol Drug Abuse 6:449-454. 
Gallager DW, Pert A, Bunney WE Jr (1978) Haloperidol-induced presynaptic dopamine supersensitivity is blocked by chronic lithium. Nature 273:309-312.

Gessa GL, Yoon K-W P, Boi V, Westfall TC, Mereu G (1986) Different anesthesia preparations reveal appropriate responses of dopamine mid-brain neurons to dopamine agonist and antagonist drugs. Soc Neurosci Abstr 12:486.

Goldstein JM, Litwin LC (1988) Spontaneous activity of A9 and A10 dopamine neurons after acute and chronic administration of the selective dopamine D1 receptor antagonist SCH 23390. Eur J Pharmacol 155:175-180.

Grace AA, Bunney BS (1986) Induction of depolarization block in midbrain dopamine neurons by repeated administration of haloperidol: Analysis using in vivo intracellular recording. J Pharmacol Exp Ther 238:1092-1100.

Hodgkin AL, Huxley AF (1952) A quantitative description of membrane current and its application to conduction and excitation in nerves. J Physiol (Lond) 1 17:500-544.

Imperato A, Puglisi-Allegre S, Casolini P, Angelucci L (1991) Changes in brain dopamine and acetilcholine release during and following stress. Are independent of the pituitary adrenocortical axis. Brain Res 538:111-117.

Mereu G, Biggio G (1990) Differential action of various allosteric modulators of $\mathrm{GABA}_{\mathrm{A}}$ receptor upon the spontaneous discharge rate of nigral neurons in vivo. In: GABA and benzodiazepine receptor subtypes (Biggio G, Costa E, eds), pp 109-125. New York: Raven.

Mereu G, Fanni B, Gessa GL (1984) General anesthetics prevent dopaminergic neuron stimulation by neuroleptics. In: Catecholamines, Pt B, Neuropharmacology and central nervous system, theo- retical aspects (Usdin E, Carlsson A, Dahlstom Engel J, eds), pp 353358. New York: Liss.

Mereu G, Westfall TC, Wang RY (1985) Modulation of terminal excitability of mesolimbic dopaminergic neurons by D-amphetamine and haloperidol. Brain Res 359:88-96.

Moghadam B, Bunney BS (1993) Depolarization inactivation of dopamine neurons: terminal release characteristics. Synapse 14:195200.

Paxinos G, Watson C (1982) The rat brain in stereotaxic coordinates. New York: Academic.

Skarsfeldt T (1988a) Differential effect after repeated treatment with haloperidol, clozapine, thioridazine and tefludazine on SNC and VTA dopamine neurons in rats. Life Sci 42:1037-1044.

Skarsfeldt T (1988b) Effect of chronic treatment with SCH 23390 and haloperidol on spontaneous activity of dopamine neurons in substantia nigra pars compacta (SNC) and ventral tegmental area (VTA) in rats. Eur J Pharmacol 145:239-243.

Tissari AH, Casu M, Gessa GL (1979) Chronic haloperidol: tolerance to the stimulating effect on striatum tyrosine hydroxylase. Life Sci 24:411-416.

Walters JR, Lakoski JM (1977) Effect of muscimol on single unit activity of substantia nigra dopamine neurons. Eur J Pharmacol 67: $469-471$.

White FJ, Wang RY (1983) Differential effect of classical and atypical antypsychotic drugs on A9 and A10 neurons. Science 221:1054-1057.

Zivkovic B, Guidotti A, Costa E (1974) Effect of neuroleptics on striatal tyrosine hydroxylase: changes in affinity for the ptcridine cofactor. Mol Pharmacol 10:727-735. 